\title{
EЛEKTPOHIKA
}

УДК 621.382

DOI https://doi.org/10.32838/2663-5941/2020.4/42

Осадчук О.В.

Вінницький національний технічний університет

Осадчук В.C.

Вінницький національний технічний університет

Осадчук Я.О.

Вінницький національний технічний університет

\section{ДОСЛІДЖЕННЯ ГЕНЕРАТОРА ЕЛЕКТРИЧНИХ КОЛИВАНЬ НА ОСНОВІ ТУНЕЛЬНО-РЕЗОНАНСНОГО ДІОДА}

На основі повної еквівалентної схеми тунельно-резонансного діода, яка враховує його ємнісні та індуктивні властивості, складено диференційне рівняння другого порядку, щчо описує фізичні процеси в коливальній системі генератора. Розв'язок рівняння дав змогу отримати аналітичну залежність вихідної змінної напруги генератора від часу, а також умови виконання стабільних синусоїдальних коливань у системі. Визначено залежність резонансної частоти від параметрів схеми і режимів живлення, а також аналітичну залежність частоти, при якій у коливальній системі генератора повністю компенсуються втрати енергії завдяки від'ємному диференційному опору. Показано, шуо резонансна частота генератора змінюється на діляниі від 'ємного диферениійного опору від $12 \cdot 10^{9} \mathrm{\Gamma u}$ до $1,8 \cdot 10^{9} \mathrm{\Gamma u}$, що пояснюється сумісним впливом зміни від 'ємного диференційного опору, власних ємності та індуктивності тунельно-резонансного діода. Використання приладів із від'ємним диференщійним опором дає змогу суттєвим чином спростити конструкторське виконання генераторів електричних коливань в усьому діапазоні радіотехнічних частот. При цьому на базі конкретного схемотехнічного рімення залежно від режимів роботи можна реалізувати як генератори гармонічних коливань, так $i$ генератори імпульсних коливань спеціальної форми. Дослідження характеристик надвисокочастотних генераторів на основі тунельно-резонансних діодів базується на еквівалентній схемі, яка не враховує індуктивної складової частини діода, хоча ия складова частина є за будь-яких умов роботи, оскільки струм, який протікає крізь прилад, завжди запізнюється стосовно напруги, яка його викликала, що відповідає індуктивній реакиії тунельно-резонансного діода. Генератор електричних коливань створено на основі тунельно-резонансного діода, вольт-амперна характеристика якого має спадну ділянку, щзо відповідає існуванню диференціального від 'ємного опору на иџй ділянці. Спадна ділянка виникає завдяки зменшенню струму, який проходить через двобар'єрну квантову гетероструктуру, зменшенню коефіцієнта прозорості потенційних бар'єрів, внаслідок збільшення енергії електронів при зростанні прикладеної напруги порівняно з енергетичним резонансним рівнем.

Ключові слова: генератор, тунельно-резонансний діод, частота, від'ємний диференційний опір, гетероструктура, наноелектронна структура.

Постановка проблеми. Розробка новітніх мікроелектронних технологій, таких як променево-епітаксіальна та газофазна епітаксіальна, які стали головними технологіями в наноелектроніці, дала змогу створити нові сучасні квантові наноструктури. На базі цих квантових гетероструктур було розбудовано унікальні наноелектронні прилади, які отримали назву «тунельно-резонансні діоди». В основі роботи цих приладів лежить ефект тунелювання електронів через квантові гетероструктури під час їх руху перпендикулярно до площини потенціальних бар'єрів, які поділяють квантові гетероструктури.

Використання приладів із від'ємним диференційним опором дає змогу суттєвим чином спростити конструкторське виконання генераторів електричних коливань в усьому діапазоні радіотехнічних частот. При цьому на базі конкретного схемотехнічного 
рішення залежно від режимів роботи можна реалізувати як генератори гармонічних коливань, так і генератори імпульсних коливань спеціальної форми. Проте дослідження характеристик надвисокочастотних генераторів на основі тунельно-резонансних діодів базується на еквівалентній схемі, яка не враховує індуктивної складової частини діода, хоча ця складова частина $є$ за будь-яких умов роботи, оскільки струм, який протікає скрізь прилад, завжди запізнюється порівняно з напругою, яка його викликала, що відповідає індуктивній реакції тунельнорезонансного діода. Тому ця робота присвячена дослідженню генератора електричних коливань, в еквівалентній схемі якого враховано вплив індуктивної складової частини діода.

Аналіз останніх досліджень і публікацій. Теоретичні основи роботи тунельно-резонансних діодів заклали Л .Есакі і Р. Тцу $[1 ; 2 ; 3]$. Дійсно, вони першими дослідили від'ємний диференційний опір у наноструктурах $\mathrm{AlGaAs} / \mathrm{GaAs}$, внаслідок резонансного тунелювання електронів крізь потенційні бар'єри. Унікальними властивостями тунельнорезонансних діодів $\epsilon$ їх надвисокочастотні властивості разом із від'ємним диференційним опором, що дало змогу будувати на їх основі логічні пристрої, прилади пам'яті, перемикачі, резонансні підсилювачі, генератори, сенсори та багато інших приладів [4, с. 454-465; 5-8; 9, с. 196-235]. Особливу увагу було приділено розробці і дослідженню генераторів електричних коливань, які можуть працювати в області терагерцових частот, втрати енергії в коливальних системах яких компенсуються від'ємним диференційним опором $[10-13 ; 14$, с. 302-307; 15 , c. $259-266]$.

Постановка завдання. Метою роботи $є$ дослідження математичної моделі генератора на основі тунельно-резонансного діода, яка враховує його ємнісні та індуктивні властивості. Для досягнення поставленої мети в роботі треба вирішити такі задачі: 1) провести аналіз та розв'язання диференційного рівняння другого порядку, що описує фізичні процеси в коливальній системі генератора на основі тунельно-резонансного діода; 2) визначити умови виконання стабільних синусоїдальних коливань у системі; 3) визначити залежність резонансної частоти від параметрів схеми і режимів живлення, а також отримати аналітичну залежність частоти, при якій у коливальній системі генератора повністю компенсуються втрати енергії завдяки від'ємному диференційному опору; 4) зробити висновки 3 проведеного дослідження.

Виклад основного матеріалу дослідження. Генератор електричних коливань створено на основі тунельно-резонансного діода, вольт-амперна характеристика якого має спадну ділянку, що відповідає існуванню диференціального від'ємного опору на цій ділянці. Спадна ділянка виникає завдяки зменшенню струму, який проходить через двобар'єрну квантову гетероструктуру, зменшенню коефіцієнта прозорості потенціальних бар'єрів, внаслідок збільшення енергії електронів при зростанні прикладеної напруги порівняно 3 енергетичним резонансним рівнем. Від'ємний диференційний опір перетворює енергію постійного електричного поля джерела напруги, що живить тунельно-резонасний діод, на енергію змінного електричного поля. Схема генератора подана на рис. 1. Електрична схема генератора (рис. 1) живиться від джерела постійної напруги $U_{ж}$, опору втрат $R_{s}$, який включає всі омічні опори схеми, зовнішньої індуктивності $L$, яка послідовно підключена до внутрішньої індуктивності діода, а також містить індуктивності виводів схеми, зовнішньої ємності $C$, яка паралельно підключена до внутрішньої ємності діода, а також сам тунельно-резонансний діод.

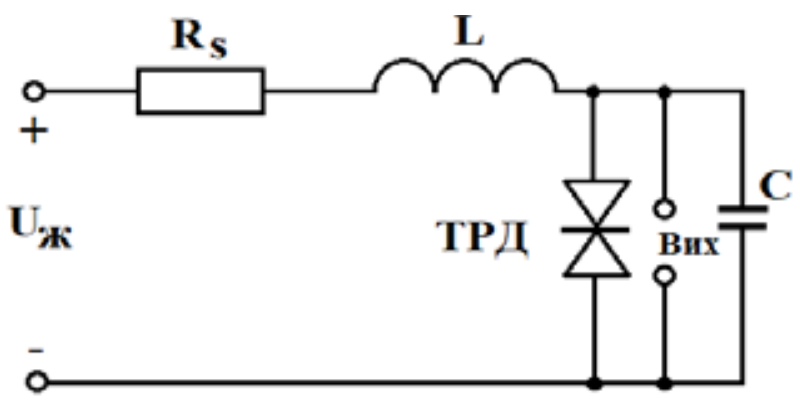

Рис. 1. Схема генератора електричних коливань на основі тунельно-резонасного діода

Еквівалентну схему генератора для розрахунків його характеристик подано на рис. 2.

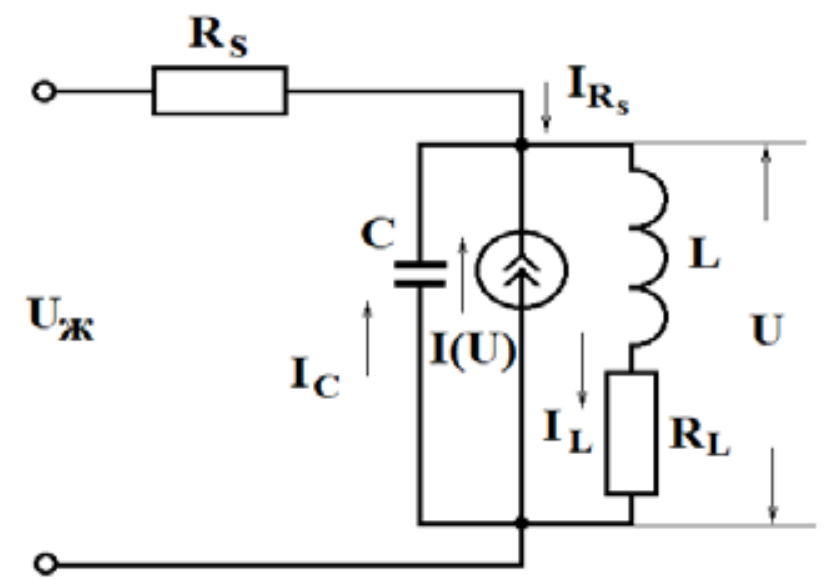

Рис. 2. Еквівалентна схема генератора електричних коливань із внутрішнім джерелом струму I(U) 
Джерело струму $I(U)$ в робочій точці на спадній ділянці вольт-амперної характеристики визначає відношення $U / I(U)$, що відповідає від'ємному диференційному опору $-R_{g}$, тому надалі в еквівалентній схемі (рис. 3) $U / I(U)$ замінюється на $-R_{g}$. Згідно з рис. 2 складемо рівняння Кірхгофа, яке необхідне для аналізу схеми генератора електричних коливань

$$
\begin{gathered}
U_{\dddot{ }}=U_{R_{S}}+L \frac{d I_{L}}{d t}+R_{L} I_{L} \\
I_{R_{S}}=-I_{C}-I(U)+I_{L}=-C \frac{d U}{d t}-I(U)+I_{L}
\end{gathered}
$$

3 рівнянь (1) i (2) знайдемо складники, які визначають розвиток процесів у схемі

$$
\begin{gathered}
\frac{d U}{d t}=\frac{-I_{R_{S}}-I(U)+I_{L}}{C}, \\
\frac{d I_{L}}{d t}=\frac{U-R_{L} I_{L}}{L},
\end{gathered}
$$

У стані рівноваги $\left(U=U_{0}\right.$ i $\left.I_{L}=I_{L 0}\right)$ струми i напруги залишаються незмінними

$$
\left.\frac{d U}{d t}\right|_{U=U_{0}}=0,\left.\frac{d I_{L}}{d t}\right|_{I_{L}=I_{L 0}}=0,
$$

3 рівнянь (3), (4) і (5) знаходимо струми і напруги в стані рівноваги

$$
\begin{gathered}
U_{\varkappa}-U_{0}=R_{s}\left(I\left(U_{0}\right)-I_{L 0}\right), \\
I_{L 0}=U_{0} / R_{L},
\end{gathered}
$$

Стан рівноваги схеми генератора електричних коливань реалізується в точці перетину спадної ділянки статичної вольт-амперної характеристики діода і лінії статичного навантаження.

Визначення стійкості стану рівноваги визначається аналітичним методом А.М. Ляпунова $[16$, с. $145-150]$. За цим методом правильну відповідь про питання стійкості станів рівноваги нелінійної системи (1) і (2) дає дослідження рівнянь іiї першого (лінійного) наближення. Для отримання цих рівнянь введемо нові змінні для системи (1) і (2)

$$
\begin{gathered}
u=U-U_{0}, \quad \text { (8) коливання. Розв'язок рівняння (15) } \\
x_{1,2}=\frac{-\left[\frac{R_{L}}{L}+\left(\frac{1}{R_{s} C}-\frac{1}{R_{g} C}\right)\right] \pm \sqrt{\left[\frac{R_{L}}{L}+\left(\frac{1}{R_{s} C}-\frac{1}{R_{g} C}\right)\right]^{2}-\frac{4}{L C}\left(\frac{R_{L}}{R_{g}}-\frac{R_{L}}{R_{s}}-1\right)}}{2},
\end{gathered}
$$

$$
i=I_{L}-I_{L 0},
$$

які описують невеликі відхилення режиму схеми генератора від параметрів рівноваги $U_{0}, I_{L 0}$. Нелінійну статичну характеристику тунельнорезонансного діода поблизу стану рівноваги замінимо лінійною функцією $I\left(U_{0}+u\right)=I\left(U_{0}\right)+\frac{u}{R_{g}}$, що включає диференціальний від'ємний опір $R_{g}$ у точці рівноваги, а нелінійні ємність $C(U)$ i індуктивність $L(U)$ в точці рівноваги будемо вважати постійними. Тоді рівняння (3) і (4) приймуть вигляд

$$
\begin{gathered}
\frac{d u}{d t}=\frac{u}{R_{s} C}-\frac{u}{R_{g} C}+\frac{i}{C}, \\
\frac{d i}{d t}=\frac{u-R_{L} i}{L},
\end{gathered}
$$

Виконавши диференціювання рівняння (10) і підставивши в нього рівняння (11), отримуємо

$$
\frac{d^{2} u}{d t^{2}}=\left(\frac{1}{C R_{s}}-\frac{1}{R_{g} C}\right) \frac{d u}{d t}+\left(\frac{u-R_{L} i}{L C}\right),
$$

У рівняння (12) підставимо замість струму $i$ його вираз

$$
i=C \frac{d u}{d t}-\frac{u}{R_{s}}+\frac{u}{R_{g}},
$$

тоді кінцевий вираз для рівняння (12) приймає вигляд

$\frac{d^{2} u}{d t^{2}}+\left[\frac{R_{L}}{L}+\left(\frac{1}{R_{s} C}-\frac{1}{R_{g} C}\right)\right] \frac{d u}{d t}+\left(\frac{R_{L}}{R_{g}}-\frac{R_{L}}{R_{s}}-1\right) \frac{u}{L C}=0$,

Згідно $з$ рівнянням (14) складемо характеристики рівняння системи

$x^{2}+x\left[\frac{R_{L}}{L}+\left(\frac{1}{R_{s} C}-\frac{1}{R_{g} C}\right)\right]+\left(\frac{R_{L}}{R_{g}}-\frac{R_{L}}{R_{s}}-1\right) \frac{1}{L C}=0$,

Стійкість стану рівноваги, за Ляпуновим, визначається властивостями коренів рівняння (15). Якщо дійсні складники коренів позитивні, то стан рівноваги є стійким, а для виникнення коливань у системі необхідно, щоб корені мали комплексне значення. Виходячи 3 цих вимог, можна записати умови, за яких у системі генератора виникають синусоїдальні коливання. Розв'язок рівняння (15) має вигляд 


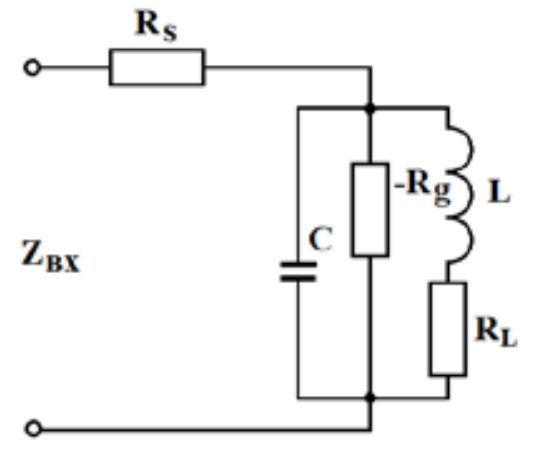

Рис. 3. Еквівалентна схема генератора

3 виразу (16) витікають умови стійкої роботи

$$
\begin{gathered}
\left|\frac{R_{L}}{L}+\left(\frac{1}{R_{s} C}-\frac{1}{R_{g} C}\right)\right|<0, \quad(17) \begin{array}{l}
\text { чимо резонансну частоту і частоту, на якій повністю } \\
\text { компенсуютья втрати енергії в коливальній системі } \\
\text { генератора. Вираз повного опору має вигляд }
\end{array} \\
Z_{6 x}=R_{s}+\frac{\left[\frac{R_{g}}{1+\left(\omega C R_{g}\right)^{2}}\right]^{2} R_{L}+\left[\frac{R_{g}}{1+\left(\omega C R_{g}\right)^{2}}\right](\omega L)^{2}+\left[\frac{\omega C R_{g}^{2}}{1+\left(\omega C R_{g}\right)^{2}}\right]^{2} R_{L}+\left[\frac{R_{g}}{1+\left(\omega C R_{g}\right)^{2}}\right] R_{L}^{2}}{\left[\frac{R_{g}}{1+\left(\omega C R_{g}\right)^{2}}+R_{L}\right]^{2}+\left[\omega L-\frac{\omega C R_{g}^{2}}{1+\left(\omega C R_{g}\right)^{2}}\right]^{2}}+ \\
+j \frac{\left[\frac{R_{g}}{1+\left(\omega C R_{g}\right)^{2}}\right]^{2}(\omega L)-\left[\frac{\omega C R_{g}^{2}}{1+\left(\omega C R_{g}\right)^{2}}\right] R_{L}^{2}-\left[\frac{\omega C R_{g}^{2}}{1+\left(\omega C R_{g}\right)^{2}}\right](\omega L)^{2}+\left[\frac{\omega C R_{g}^{2}}{1+\left(\omega C R_{g}\right)^{2}}\right]^{2}(\omega L)}{\left[\frac{R_{g}}{1+\left(\omega C R_{g}\right)^{2}}+R_{L}\right]^{2}+\left[\omega L-\frac{\omega C R_{g}^{2}}{1+\left(\omega C R_{g}\right)^{2}}\right]^{2}}
\end{gathered}
$$

$$
\left|\frac{1}{L C}\left(\frac{R_{L}}{R_{g}}-\frac{R_{L}}{R_{s}}-1\right)\right|>0,
$$

Розв'язок рівняння (14) дає залежність вихідної напруги генератора від часу і описується виразом

$$
u(t)=A \exp \left(x_{1} t\right)+B \exp \left(x_{2} t\right),
$$

де $x_{1}$ i $x_{2}$ корені рівняння (15), які визначаються виразом (16), $A$ і $B$ - постійні інтегрування, що знаходяться 3 початкових умов.

На основі еквівалентної схеми (рис. 3) розрахуємо повний вхідний опір $Z_{6 x}$, на основі якого визна-

Порівнявши нулю уявну складову частину рівняння (20), визначимо резонансну частоту $f_{\text {рез }}$ 3 рівняння, яке описується формулою

$$
\omega^{4}\left(R_{g}^{4} C^{3} L^{2}\right)+\omega^{2}\left(C^{3} R_{g}^{4} R_{L}^{2}+C R_{g}^{2} L^{2}-R_{g}^{4} C^{2} L\right)+\left(C R_{g}^{2} R_{L}^{2}-R_{g}^{2} L\right)=0,
$$

Розв'язок рівняння (21) є вираз

$$
f_{\text {pe3 }}=\frac{1}{2 \pi}\left[\frac{-b \pm \sqrt{b^{2}-4 a d}}{2 a}\right]^{1 / 2}
$$

де $a=R_{g}^{4} C^{3} L^{2} ; b=C^{3} R_{g}^{4} R_{L}^{2}+C R_{g}^{2} L^{2}-R_{g}^{4} C^{2} L ; d=C R_{g}^{2} R_{L}^{2}-R_{g}^{2} L$.

Рівняння для визначення частоти $f_{R=0}$, за якої втрати енергії в коливальній системі генератора дорівнюють нулю, отримаємо, прирівнявши нулю дійсну складову частину виразу (20). Таким чином, рівняння має вигляд

$$
\begin{gathered}
\omega^{4}\left(R_{s} R_{L}^{2} C^{4} R_{g}^{4}+L^{2} C^{2} R_{g}^{2} R_{s}-L C^{3} R_{g}^{4} R_{s}+R_{g}^{3} L^{2} C^{2}\right)+\omega^{2}\left(2 R_{L}^{2} C^{2} R_{g}^{2} R_{s}+\right. \\
\left.+2 R_{s} R_{g}^{3} R_{L} C^{2}+R_{s} C^{2} R_{g}^{4}-2 R_{s} L C R_{g}^{2}+R_{s} L^{2}+R_{g} L^{2}+C^{2} R_{g}^{4} R_{L}+R_{g}^{3} R_{L}^{2} C^{2}\right)+ \\
+\left(R_{g}^{2} R_{s}+2 R_{s} R_{g} R_{L}+R_{g}^{2} R_{L}+R_{g} R_{L}^{2}\right)=0 .
\end{gathered}
$$

Розв'язок рівняння (23) дає значення для $f_{R=0}$

$$
f_{R=0}=\frac{1}{2 \pi}\left[\frac{-n \pm \sqrt{n^{2}-4 m l}}{2 m}\right]^{1 / 2},
$$

де $m=R_{s} R_{L}^{2} C^{4} R_{g}^{4}+L^{2} C^{2} R_{g}^{2} R_{s}-L C^{3} R_{g}^{4} R_{s}+R_{g}^{3} L^{2} C^{2} ; l=R_{g}^{2} R_{s}+2 R_{s} R_{g} R_{L}+R_{g}^{2} R_{L}+R_{g} R_{L}^{2}$.

$n=2 R_{L}^{2} C^{2} R_{g}^{2} R_{s}+2 R_{s} R_{g}^{3} R_{L} C^{2}+R_{s} C^{2} R_{g}^{4}-2 R_{s} L C R_{g}^{2}+R_{s} L^{2}+R_{g} L^{2}+C^{2} R_{g}^{4} R_{L}+R_{g}^{3} R_{L}^{2} C^{2} ;$ 


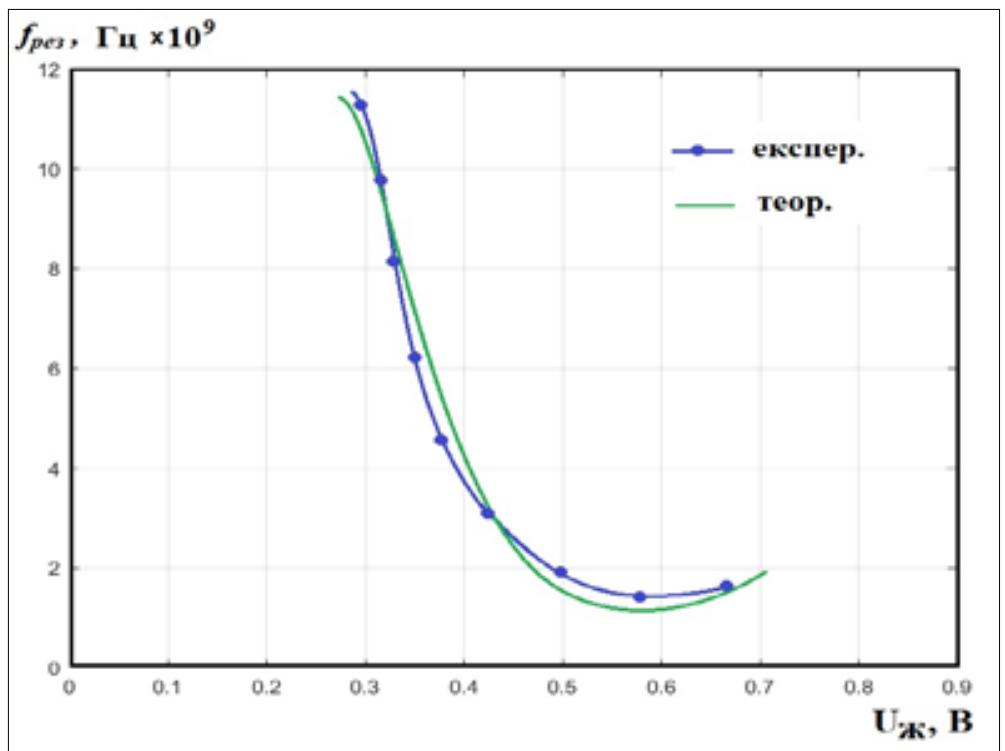

Рис. 4. Теоретична та експериментальна залежності резонансної частоти від зміни напруги живлення генератора

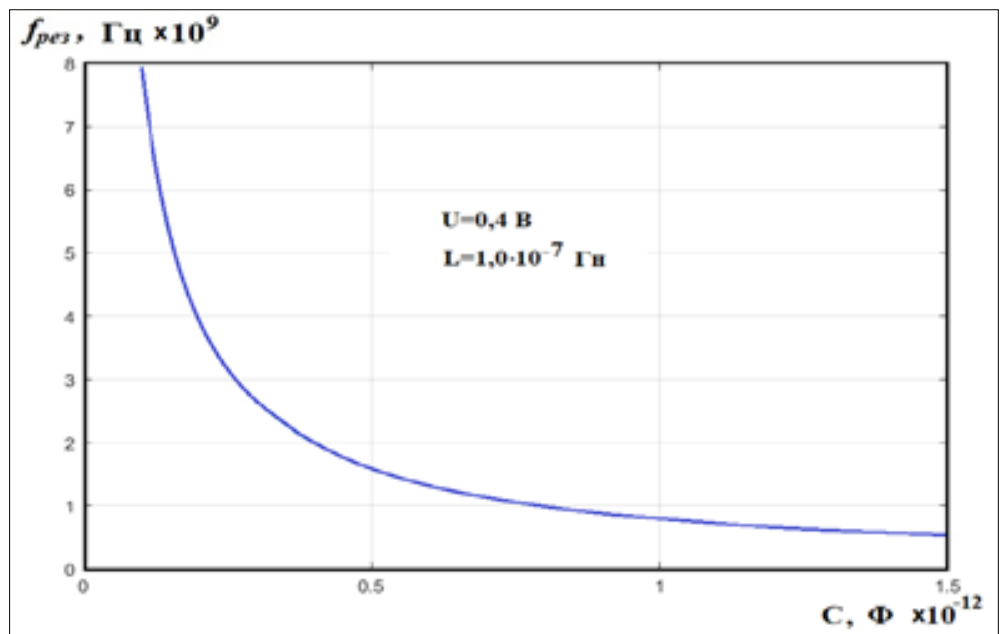

Рис. 5. Теоретична залежність зміни резонансної частоти генератора від зміни зовнішньої смності

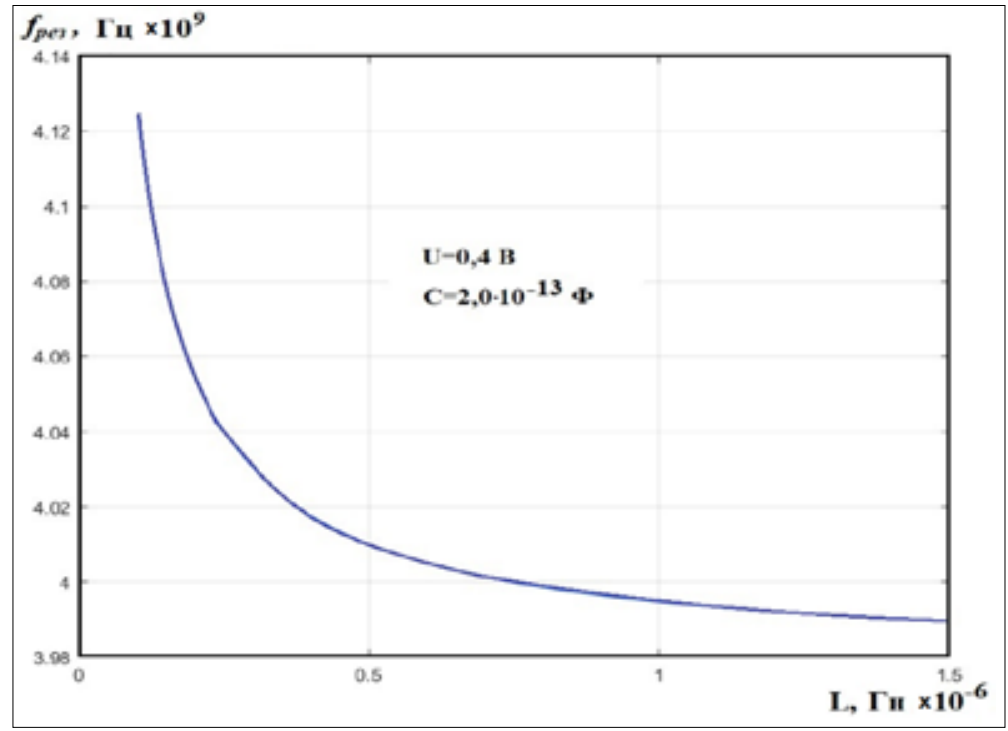

Рис. 6. Теоретична залежність резонансної частоти генератора від зміни зовнішньої індуктивності 
На рис. 4 подано теоретичну та експериментальну залежності резонансної частоти від зміни напруги живлення генератора на спадній ділянці вольт-амперної характеристики. Як видно з графіка, резонансна частота зменшується майже за лінійним законом, що пояснюється зміною величини від'ємного диференційного опору на спадній ділянці вольт-амперної характеристики тунельно-резонансного діода, а також зміною власних ємності та індуктивності діода. Розкид теоретичної і експериментальної кривих становить $\pm 2,5 \%$.
На рис. 5 представлено залежність резонансної частоти від зміни зовнішньої ємності генератора. Як видно 3 рис. 5, резонансна частота різко зменшується зі збільшенням зовнішньої ємності до $0,5 \cdot 10^{-12} \Phi$, а подальше зростання зовнішньої ємності в значно меншій степені впливає на резонансну частоту генератора. Це пояснюється тим, що при малих значеннях зовнішньої ємності коливальної системи генератора на резонансну частоту значно впливає власна ємність тунельно-резонансного діода.

На рис. 6 наведено залежність резонансної частоти від зміни зовнішньої індуктивності

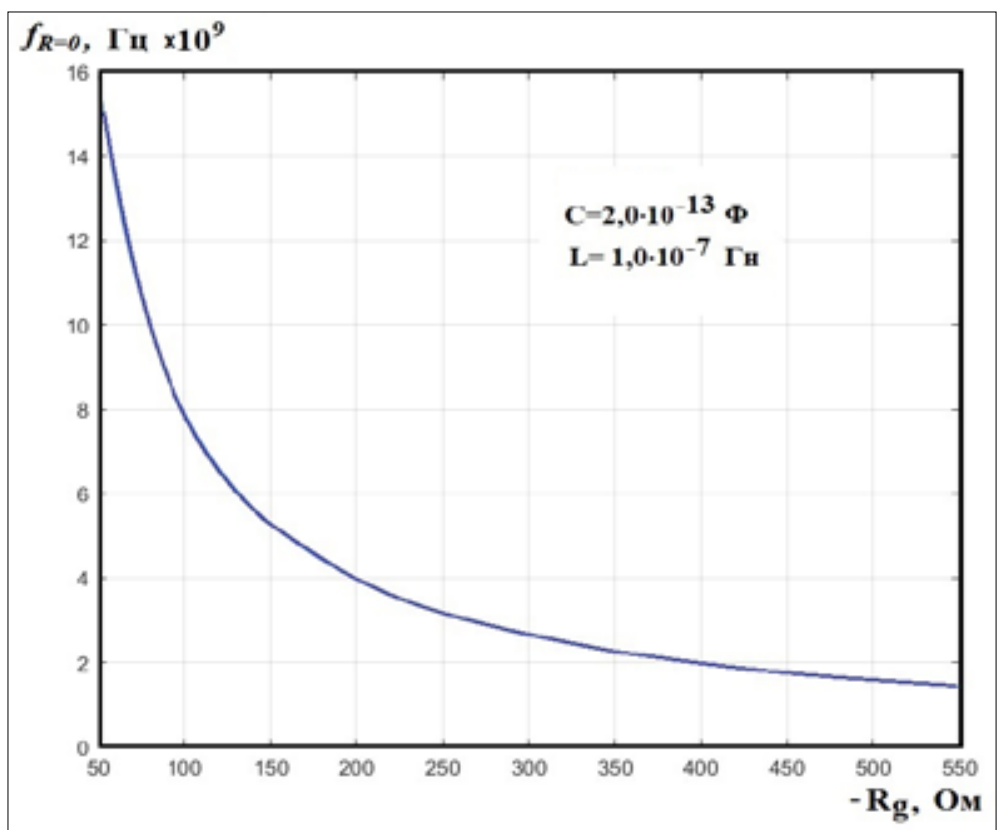

Рис. 7. Теоретична залежність частоти $f_{R=0}$ від зміни величини від'ємного диференційного опору

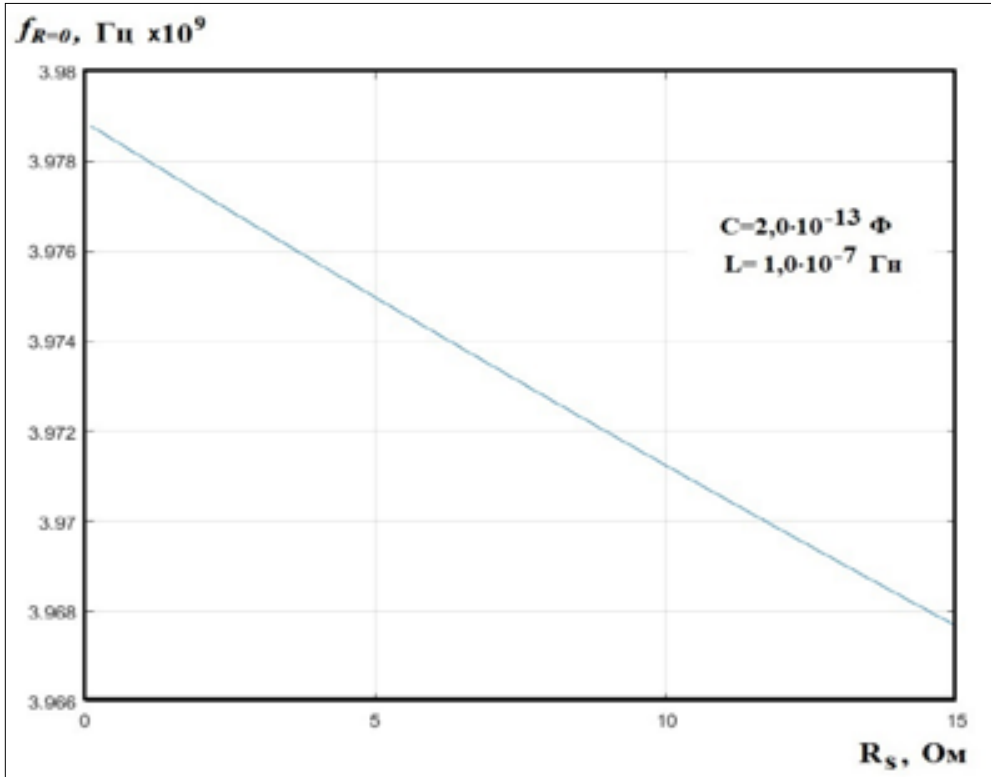

Рис. 8. Теоретична залежність частоти $f_{R=0}$ від зміни зовнішнього активного опор 
коливальної системи генератора. Поведінка зміни резонансної частоти зі зростанням зовнішньої індуктивності така сама, як і для ємності, і пояснюється тими самими причинами.

На рис. 7 подано залежність частоти $f_{R=0}$, при якій повністю компенсуються втрати енергії в коливальній системі генератора, від зміни від'ємного диференційного опору. Як видно 3 рис. 7, частота $f_{R=0}$, зменшується в широкому діапазоні від $16 \cdot 10^{9}$ Гц до $1,8 \cdot 10^{9}$ Гц при зміні диференційного опору на спадній ділянці вольтамперної характеристики діода. Цей спад частоти $f_{R=0}$ пояснюється як зміною самого від'ємного диференційного опору, так і зміною власних індуктивності та ємності тунельно-резонансного діода.

На рис. 8 наведено залежність частоти $f_{R=0}$ від зміни зовнішнього активного опору $R_{s}$. Як видно 3 графіка, частота $f_{R=0}$ лінійно зменшується при зростанні активного опору $R_{s}$. Це пояснюється тим, що він додається до активної складової частини повного вхідного опору схеми і лінійно змен- шує величину від'ємного диференційного опору, який разом із внутрішніми власними ємністю та індуктивністю зменшують частоту $f_{R=0}$.

Висновки. На основі повної еквівалентної схеми тунельно-резонансного діода, яка враховує його ємнісні та індуктивні властивості, складено диференційне рівняння другого порядку, що описує фізичні процеси в коливальній системі генератора. Розв'язок рівняння дав змогу отримати аналітичну залежність вихідної змінної напруги генератора від часу, а також умови виконання стабільних синусоїдальних коливань у системі.

Визначено аналітичні залежності резонансної частоти генератора та частоти, за якої втрати енергії в коливальній системі генератора повністю компенсуються енергією від'ємного диференційного опору. Показано, що резонансна частота генератора змінюється на ділянці від'ємного диференційного опору від $12 \cdot 10^{9}$ Гц до $1,8 \cdot 10^{9}$ Гц, що пояснюється сумісним впливом зміни від'ємного диференційного опору, власних ємності та індуктивності тунельно-резонансного діода.

\section{Список літератури:}

1. Esaki L. and Tsu R. Superlattics and negative differential conductivity in semiconductors. IBM J. Res. Develop, 1970. Vol. 14. Jan. P. 61-65.

2. Tsu R. and Esaki L. Tunneling in a finite superlattice. Appl. Phys. Lett. 1973. June, vol. 22. P. 562-564.

3. Chand L.L., Esaki L. and Tsu R. Resonant tunneling in semiconductor double barriers. Appl. Phys. Lett. 1974. Vol. 24. June. P. 593-595.

4. Sze S.M. and Kwok K. Ng. Physics of Semiconductor Devices Wiley-Interscience. USA. ISBN-13: 978-0-471-14323-9. 815 p. 2007.

5. Awan, Jram Taj. Optical and Transport of p-i-n GaAs-AlAs resonant tunneling diode. Jram Taj Awan Sao Carlos: UFS Car, 2014, P.85.

6. Halimatus Saadiah, Warsuzarina Mat Jubadi, Nabihah Ahmad and M. Hairol Jabbar. Resonant Tunneling Diode Design for Oscillator Circuit. International Postgraduate Conference. Physics. 2017. P. 1-8.

7. Jan-Frederik Mennemann, Ansgar Jüngel,Hans Kosina. Transient Schrodinger-Poisson Simulations of a High-Frequency Resonant Tunneling Diode Oscillator. Journal of Computational Physics. Volume 239, 15 April 2013. P. 187-205.

8. Man Mohan Singh, M.J. Siddiqui, Anupriya Saxena. Comparative Simulation of GaAs and GaN basedDouble Barriers-Resonant tunneling Diode. Proceedings of the International Conference on Computational Modeling and Security (CMS 2016). P. 581-587. doi: 10.1016/j.procs.2016.05.224

9. Осадчук В.С., Осадчук А.В. Реактивные свойства транзисторов и транзисторных схем. Винница : «Универсум-Винница», 1999. 275 с.

10. Осадчук В.С., Осадчук О.В., Осадчук Я.О. Мікроелектронний перетворювач тиску з частотним виходом на основі тунельно-резонансного діода. Вісник Хмельницького національного університету. Технічні науки. 2015. № 1 (221). С. 97-101.

11. Osadchuk V.S., Osadchuk A.V. Radiomeasuring Microelectronic Transducers of Physical Quantities. Proceedings of the 2015 International Siberian Conference on Control and Communications (SIBCON). 21-23 May 2015. Omsk. DOI: 10.1109/SIBCON.2015.7147167

12. Osadchuk I.A., Osadchuk A.V., Osadchuk V.S. and Semenov A.O. Nanoelectronic Pressure Transducer with a Frequency Output Based on a Resonance Tunnel Diode. 2020 IEEE 15th International Conference on Advanced Trends in Radioelectronics, Telecommunications and Computer Engineering (TCSET), Lviv-Slavske, Ukraine. 2020. P. 452-457. doi: 10.1109/TCSET49122.2020.235474.

13. Osadchuk V.S., Osadchuk A.V. The Microelectronic Radiomeasuring Transducers of Magnetic Field with a Frequency Output. Elektronika ir Elektrotechnika. Kaunas : Techolodija. 2011. № 4 (110). P. 67-70. URL: http://dx.doi.org/10.5755/j01.eee.110.4.289 
14. Мартинес-Дуарт Дж. М. Нанотехнологии для микро- и оптоэлектроники / Дж. М. Мартинес-Дуарт, Р.Дж. Мартин-Палма, Ф. Агулло-Руеда. Москва : Техносфера, 2009. 368 с.

15. Наноэлектроника: теория и практика : учебник / В.Е. Борисенко, А.И. Воробьева, А.Л. Данилюк, Е.А. Уткина. 2-е изд., перераб. и доп. Москва : БИНОМ. Лаборатория знаний, 2013. 366 с.

16. Андреев В.С. Теория нелинейных электрических цепей : Учебное пособие для вузов. Москва : Радио и связь, 1982. 280 с.

\section{Osadchuk A.V., Osadchuk V.S., Osadchuk Ya.A. INVESTIGATION OF THE GENERATOR ELECTRICAL FLUCTUATIONS ON THE BASIS OF A RESONANT TUNNELING DIODE}

Based on the full equivalent circuit of the tunnel resonance diode, which takes into account its capacitive and inductive properties, a second-order differential equation is described that describes the physical processes in the oscillatory system of the generator. The solution of the equation made it possible to obtain the analytical dependence of the output alternating voltage of the generator on time, as well as the conditions for stable sinusoidal oscillations in the system. The dependence of the resonant frequency on the parameters of the circuit and power modes, as well as the analytical dependence of the frequency at which energy losses due to negative differential resistance in the oscillator system are completely compensated, are determined. It is shown that the resonant frequency of the generator varies in the region of negative differential resistance from $12 \cdot 10^{9} \mathrm{~Hz}$ to $1.8 \cdot 10^{9} \mathrm{~Hz}$, which is explained by the combined influence of changes in negative differential resistance, intrinsic capacitance, and inductance of the tunnel resonance diode. The use of devices with negative differential resistance can significantly simplify the design of generators of electrical oscillations in the entire range of radio frequencies. Moreover, on the basis of a specific circuitry solution, depending on the operating modes, it is possible to implement both harmonic oscillation generators and special-shape pulse oscillators. The study of the characteristics of microwave generators based on tunnel resonance diodes is based on an equivalent circuit, it does not completely take into account the inductive component of the diode, although this component exists under any operating conditions, since the current that flows through the device is always delayed in relation to the voltage that caused it, which corresponds to the inductive reaction of the tunnel resonance diode. The electric oscillation generator is based on a tunnel resonance diode, the currentvoltage characteristic of which has a complex section corresponding to the existence of differential negative resistance in this section. The descending section occurs due to a decrease in the current passing through the double-barrier quantum heterostructure, due to a decrease in the transparency coefficient of potential barriers, due to an increase in the electron energy with an increase in the applied voltage compared to the energy resonance level.

Key words: generator, tunnel resonance diode, frequency, negative differential resistance, heterostructure, nanoelectronic structure. 